\title{
ISOLASI SENYAWA KIMIA STIGMASTAN-3,5-DIENA YANG MEMPUNYAI DAYA TOKSIK DARI DAUN EKALIPTUS (Eucalyptus deglupta Blume.)
}

\author{
ISOLATION AND TOXICITY TEST OF STIGMASTAN-3,5-DIEN \\ FROM Eucalyptus deglupta Blume.
}

\author{
Sari Setianingsih $^{* 1}$, Rudi Kartika ${ }^{1}$, Partomuan Simanjuntak ${ }^{2,3}$ \\ 1 Jurusan Kimia, Fakultas Matematika dan Ilmu Pengetahuan Alam, Universitas Mulawarman, Samarinda \\ ${ }^{2}$ Puslit Bioteknologi, Lembaga Ilmu Pengetahuan Indonesia (LIPI), Jalan Raya Bogor KM 46, Cibinong 16911; \\ ${ }^{3}$ Fakultas Farmasi, Universitas Pancasila, Jagakarsa, Jakarta 12640 \\ *Corresponding Author : sarisetianingsih10@gmail.com
}

Submit : 06 Oktober 2017 Accepted : 06 November 2017

\begin{abstract}
This study was started by extraction of Eucalyptus deglupta Blume. Using organic solvent (n-hexane, ethyl acetate, ethanol and water) followed by phytochemical screening and toxicity test using Brine Shrimp Lethality Test (BSLT) method. Isolation and identification of chemical compounds contained in the fraction were done by column chromatography and Gas Chromatography-Mass Spectrometry (GC-MS) analysis. Phytochemical screening revealed the presence of alkaloids, flavonoids, steroids and phenolics in the extract. Toxicity test results showed that the ethyl acetate extract was potentially active with $\mathrm{LC}_{50}$ value of 617.95 ppm. The extract was continued to isolation stage and gave fraction EKEA-3.1 with $\mathrm{LC}_{50}$ value of 2759.93 ppm. Identification of chemical compounds in EKEA-3.1 with KG-MS analysis showed that EKEA-3.1 was suspected to be Stigmastan-3,5-diene.
\end{abstract}

Keywords: Eucalyptus deglupta Blume.; Myrtaceae; Brine Shrimp Lethality Test (BSLT); stigmastan-3,5diene

\section{PENDAHULUAN}

Indonesia merupakan negara terbesar yang terkenal dengan kekayaan alamnya khususnya pada keanekaragaman hayati. Salah satu adalah tumbuhan yang memiliki khasiat sebagai obat yang sudah digunakan oleh masyarakat Indonesia. Tumbuhan obat tersebut digunakan sebagai obat tradisional karena proses pembuatannya secara sederhana.

Masyarakat di pulau Kalimantan, khususnya yang tinggal di pedalaman masih menggunakan tumbuhan obat secara tradisional karena sangat mudah dijangkau dan masih kurangnya pelayanan kesehatan. Mereka menggunakan obat tradisional secara turun menurun dan sudah dipercaya dapat menyembuhkan penyakit. Salah satu adalah tumbuhan obat tanaman ekaliptus (Eucalyptus deglupta Blume).

Ekaliptus merupakan tumbuhan yang memiliki banyak manfaat selain digunakan sebagai bahan industri, ekaliptus juga dimanfaatkan sebagai tanaman obat. Tumbuhan ekaliptus juga memiliki keunikan yaitu dia dapat berkembang atau tumbuh secara cepat setelah kebakaran. Secara umum, tumbuhan ekaliptus dikenal sebagai tumbuhan kayu putih [1].

Menurut Chevallier [2], ekaliptus digunakan sebagai tumbuhan obat untuk menyembuhkan penyakit infeksi, demam dan rematik selain itu juga sebagai antiseptik untuk penyakit flu dan sakit tenggorokan.

Berdasarkan penelitian sebelumnya yang dilakukan oleh Ragasa et al., [3], ekaliptus umumnya memiliki kandungan senyawa kimia flavonoid, terpenoid dan tanin.

Sehingga tujuan penelitian ini adalah untuk mengetahui senyawa metabolit sekunder yang terdapat dalam daun ekaliptus yang mempunyai daya toksik terhadap larva udang (Artemia salina).

\section{METODE PENELITIAN \\ Bahan}

Bahan yang digunakan adalah pelarut $n$ heksana, pelarut etil asetat, pelarut etanol, pelarut air, celite, lempeng KLT, silika, air laut, telur udang Artemia, sampel daun ekaliptus, serium 
sulfat $10 \%$, larutan $\mathrm{HCl} 10 \%$, reagen Dragendorff, reagen Liebermann-Bourchard, $\mathrm{FeCl}_{3} 1 \%$, pita $\mathrm{Mg}, \mathrm{HCl}_{(\mathrm{p})}$ dan DMSO.

Alat

Alat-alat yang digunakan adalah seperangkat alat gelas, rotary evaporator, spektrofotometer UV, kromatografi KG-MS.

\section{Prosedur Penelitian}

Simplisia daun ekaliptus sebanyak 500 gram diekstraksi dengan cara maserasi menggunakan pelarut $n$-heksana, etil asetat dan etanol sebanyak 6 kali pengulangan sedangkan dengan pelarut air dengan cara direfluks sebanyak 3 kali pengulangan. Kemudian filtratnya dipekatkan dengan rotary evaporator. Ekstrak yang diperoleh ditimbang dan dilanjutkan dengan uji skrining fitokimia, uji toksisitas dengan metode BSLT (Brine Shrimp Lethality Test), kromatografi kolom dan KLT preparatif. Identifikasi senyawa kimia dilakukan dengan pengambilan data spektra Kromatografi GasSpektra Massa (KG-SM) untuk mengetahui berat molekul dari senyawa kimia tersebut dan untuk mengetahui ion-ion fragmen yang terbentuk dari senyawa tersebut.

\section{HASIL DAN PEMBAHASAN \\ Hasil Determinasi}

Hasil determinasi tanaman yang dilakukan di Herbarium Bogoriense Pusat Penelitian Biologi LIPI, Cibinong, menyatakan bahwa tanaman yang digunakan pada penelitian ini adalah Ekaliptus (Eucalyptus deglupta Blume.) dari suku Myrtaceae.

\section{Hasil Ekstraksi}

Nilai persen rendemen dari masing-masing ekstrak daun ekaliptus dapat dilihat pada Tabel 1.

Tabel 1. Hasil persen rendemen masing-masing ekstrak daun ekaliptus (Eucalyptus deglupta Blume.)

\begin{tabular}{|c|c|c|c|c|c|}
\hline \multirow[b]{2}{*}{ No. } & \multirow[b]{2}{*}{ Ekstrak } & \multicolumn{3}{|c|}{ Bob ot (gram) } & \multirow{2}{*}{$\begin{array}{c}\text { Rendemen } \\
(\%)\end{array}$} \\
\hline & & $\begin{array}{c}\text { Botol } \\
\text { Kosong }\end{array}$ & $\begin{array}{c}\text { Botol + Ekstrak } \\
\text { Sampel }\end{array}$ & $\begin{array}{l}\text { Ekstrak } \\
\text { Sampel }\end{array}$ & \\
\hline 1. & $n$-heksana & 129,4991 & 124,5138 & 4,9853 & 0,99 \\
\hline 2. & Etil ase tat & 152,5723 & 124,8220 & 27,7503 & 5,55 \\
\hline 3. & Etanol & 152,9797 & 124,6009 & 28,3788 & 5,67 \\
\hline 4. & Air & 147,6328 & 125,5517 & 22,0811 & 4,42 \\
\hline
\end{tabular}

Berdasarkan hasil persen rendemen tersebut dapat dilihat bahwa pada ekstrak etanol memiliki nilai persen rendemen paling banyak yaitu sebesar
5,67 \%. Hal tersebut menunjukkan bahwa senyawa yang terbanyak pada sampel tersebut merupakan senyawa polar.

\section{Hasil Uji Skrining Fitokimia}

Uji skrining fitokimia dilakukan untuk mengetahui senyawa metabolit sekunder yang terdapat dalam ekstrak kasar dari tumbuhan [4].

Berdasarkan hasil uji skrining fitokimia pada masing-masing ekstrak daun ekaliptus (Eucalyptus deglupta Blume) dapat dilihat pada Tabel 2.

Tabel 2. Hasil uji skrining fitokimia sampel daun ekaliptus (Eucalyptus deglupta Blume.) terhadap masing-masing ekstrak.

\begin{tabular}{|c|l|c|c|c|c|}
\hline No. & \multicolumn{1}{|c|}{ UjiFitokimia } & N-heksana & EtilAsetat & Etanol & Air \\
\hline 1. & Alkaloid & - & + & + & - \\
\hline 2. & Favonoid & + & + & + & + \\
\hline 3. & Ttiterpenoid/Steroid & $+/-$ & -+ & $+/-$ & +- \\
\hline 4. & Fenolik & - & + & + & + \\
\hline 5. & Saponin & - & - & - & - \\
\hline
\end{tabular}

Senyawa metabolit sekunder pada ekstrak $n$-heksana positif flavonoid dan triterpenoid; ekstrak etil asetat positif alkaloid, flavonoid, steroid dan fenolik; ekstrak etanol positif alkaloid, flavonoid, triterpenoid dan fenolik; dan ekstrak air positif flavonoid dan fenolik. Senyawa tersebut dikatakan positif karena dilihat dari perubahan warna yang terbentuk akibat dari adanya reaksi yang terjadi pada sampel ketika ditambahkan dengan pereaksi yang digunakan pada uji tersebut.

\section{Uji Toksisitas dengan Metode BSLT}

Uji toksisitas dengan menggunakan Brine Shrimp Lethality Test ini dapat ditentukan dari jumlah kematian Artemia salina Leach akibat pengaruh ekstrak atau senyawa bahan alam dengan konsentrasi tertentu yang dinyatakan dalam $\mathrm{LC}_{50}$ merupakan angka konsentrasi ekstrak yang dapat menyebabkan kematian sebesar 50\% dari jumlah hewan uji. Hasil uji dinyatakan toksik terhadap Artemia salina Leach apabila ekstrak tumbuhan tersebut memiliki $\mathrm{LC}_{50}<1000 \mu \mathrm{g} / \mathrm{mL}$ [5].

Berdasarkan perhitungan nilai $\mathrm{LC}_{50}$ menggunakan analisis SPSS terhadap ekstrak $n$ heksana, etil asetat, etanol dan air pada daun ekaliptus, maka diperoleh nilai $\mathrm{LC}_{50}$ dapat dilihat pada Tabel 3. 
Tabel 3. Nilai $\mathrm{LC}_{50}$ pada masing-masing ekstrak daun ekaliptus (Eucalyptus deglupta Blume).

\begin{tabular}{|c|l|c|}
\hline No. & Ekstrak Sampel Daun Ekaliptus & Nilai LC 50 ppm \\
\hline 1. & Ekstrak $n$-heksana & 958,05 \\
\hline 2. & E kstrak etil asetat & 617,95 \\
\hline 3. & Ekstrak etanol & 867,00 \\
\hline 4. & Ekstrak air & 2250,85 \\
\hline
\end{tabular}

Berdasarkan hasil uji toksisitas tersebut di atas dapat diketahui bahwa ekstrak sampel daun ekaliptus yang mampu membunuh populasi larva udang sampai 50\% adalah pada ekstrak etil asetat dengan $\mathrm{LC}_{50}$ paling kecil. Sehingga ekstrak tersebut yang dilanjutkan ke tahap pemisahan menggunakan kromatografi kolom.

\section{Pemisahan dengan Kromatografi Kolom untuk Ekstrak Etil Asetat}

Hasil kromatografi kolom ekstrak etil asetat $\left(\mathrm{SiO}_{2} ; n\right.$-heksana-etil asetat $=10: 1 \sim 1: 1$, dan etil asetat) mengahasilkan 7 fraksi (EKEA-1 EKEA7) dengan nilai $\mathrm{LC}_{50}$ toksisitas (BSLT) dapat dilihat pada Tabel 4.

Tabel 4. Nilai $\mathrm{LC}_{50}$ fraksi etil asetat daun ekaliptus (Eucalyptus deglupta Blume) dari hasil kromatografi kolom I

\begin{tabular}{|c|l|c|}
\hline No. & \multicolumn{1}{|c|}{ Fraksi } & Berat (gram) \\
\hline 1. & I & 0,12 \\
\hline 2. & II & 0,09 \\
\hline 3. & III & 0,10 \\
\hline 4. & IV & 0,11 \\
\hline 5. & V & 0,08 \\
\hline 6. & VI & 0,28 \\
\hline 7. & VII & 0,13 \\
\hline
\end{tabular}

Berdasarkan hasil uji toksisitas pada tujuh fraksi hasil kolom I dapat dilihat bahwa fraksi EKEA-3 memiliki nilai $\mathrm{LC}_{50}$ yang paling kecil yaitu sebesar 950,90 ppm dibandingkan fraksi yang lain. Hal ini menunjukkan bahwa pada fraksi EKEA-3 mengandung senyawa kimia berpotensi aktif sehingga menyebabkan kematian organisme mencapai 50\%. Kemudian fraksi EKEA-3 ini dilanjutkan untuk pemisahan dengan kromatografi kolom tahap 2.

\section{Kromatografi Kolom untuk Fraksi EKEA-3}

Hasil kromatografi kolom untuk fraksi EKEA-3 $\left(\mathrm{SiO}_{2} ; n\right.$-heksana-etil asetat $=20: 1 \sim$ 10:1) menghasilkan 2 fraksi yaitu EKEA-3.1 dan EKEA-3.2. Hasil uji toksisitas dapat dilihat pada Tabel 5.

Tabel 5. Nilai $\mathrm{LC}_{50}$ fraksi etil asetat daun ekaliptus (Eucalyptus deglupta Blume.) dari hasil kromatografi kolom tahap 2

\begin{tabular}{|c|l|c|}
\hline No. & \multicolumn{1}{|c|}{ Fraksi } & NilaiLC $_{50} \mathrm{ppm}$ \\
\hline 1. & EKEA-3.1 & $\mathbf{2 7 5 9 , 9 3}$ \\
\hline 2. & EKEA-3.2 & 1430,67 \\
\hline
\end{tabular}

\section{Identifikasi Fraksi EKEA-3.1 dengan Metode Kromatografi Gas-Spektroskopi Massa (KG- MS)}

Berdasarkan analisis KG-MS pada isolat EKEA-3.1 diperoleh hasil yang menunjukkan bahwa isolat tersebut masih mengandung beberapa senyawa kimia yang dapat dilihat dari puncak kromatogram yang terbentuk. Menurut database W8N08.L. senyawa kimia yang terdapat dalam isolat EKEA-3.1 adalah campuran dari 4 senyawa yaitu: senyawa 1-docosene, senyawa (4,5-dimethoxy-2-methyl-1-naphthyl)-6,8-

dimethoxy-1,2,3-trimethyl-1,2,3,4-

tetrahydroisoquinoline, senyawa stigmastan-3,5diene dan senyawa cholest-4-en-3-one,26-hydroxy yang memiliki tingkat kemiripan antara 47 sampai $90 \%$.

Hasil penelusuran pustaka menunjukkan bahwa kandungan senyawa kimia yang terdapat dalam fraksi EKEA-3.1 diduga senyawa stigmastan-3,5-diene dengan tingkat kemiripan 64 $\%$ dan berat molekul 396. Karena senyawa kimia tersebut banyak terdapat dalam tanaman sebagai metabolit sekunder dan senyawa tersebut termasuk dalam golongan senyawa steroid. Hasil fragmentasi senyawa tersebut dapat dilihat pada Gambar 1 dan struktur kimia pada Gambar 2. 


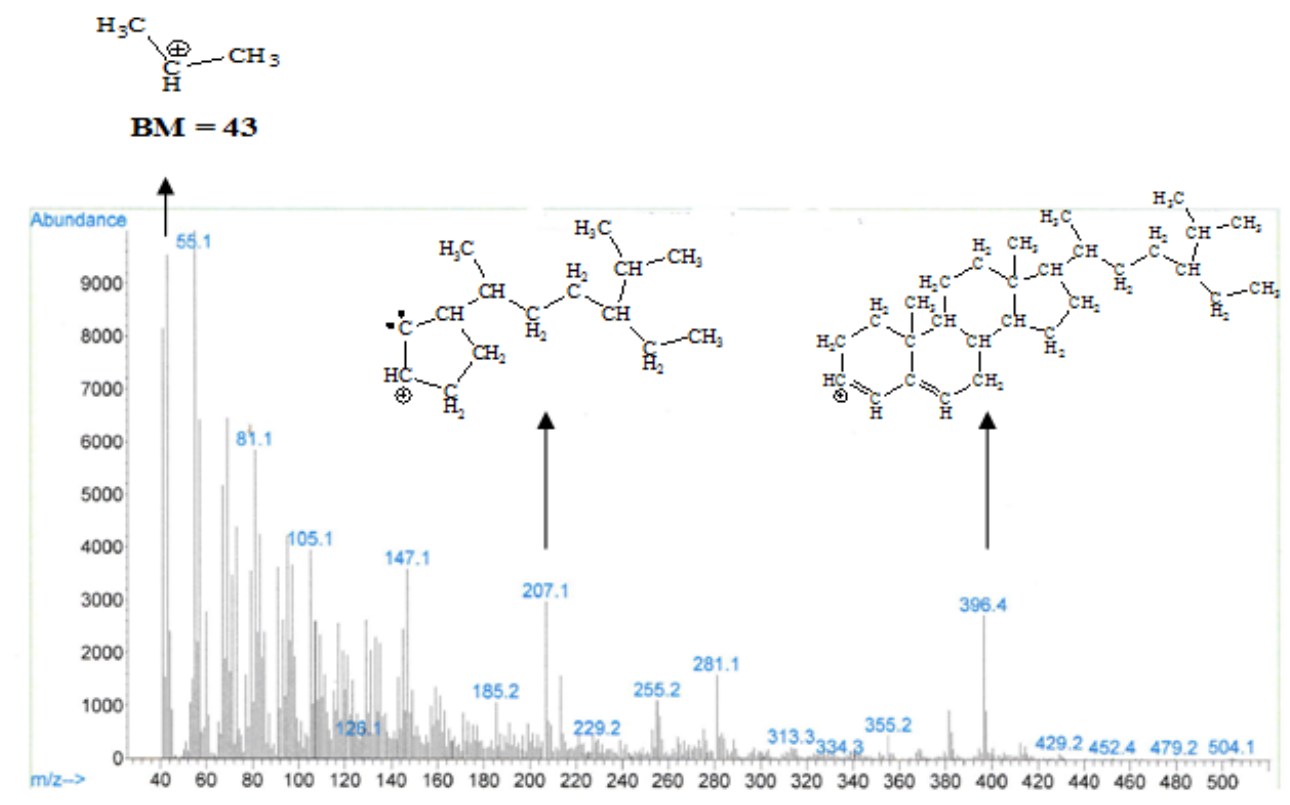

Gambar 1. Hasil analisis fragmentasi senyawa stigmastan-3,5-diena dengan analisis KG-MS

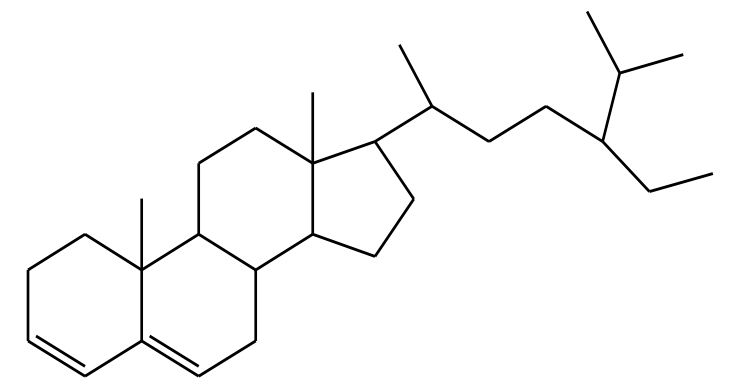

Gambar 2. Struktur kimia stigmastan-3,5-diena

\section{KESIMPULAN}

Senyawa metabolit sekunder yang mempunyai daya toksik terhadap larva udang diperkirakan adalah senyawa stigmastan-3,5-diena yang diperoleh dari isolat fraksi EKEA-3.1 dan termasuk golongan senyawa steroid.

\section{DAFTAR PUSTAKA}

[1] Chevallier, A. 2000. Encyclopedia Of Herbal Medicine 2nd American Edition. New York: Dorling Kindersley Ltd.

[2] Chevallier, A. 2000. Encyclopedia Of Herbal Medicine 2nd American Edition. New York: Dorling Kindersley Ltd.
[3] Ragasa, C. Y., Jr, V. D. E., Reyes, M. M. D. L., \& Shen, C. 2015. Terpenoids from Eucalyptus deglupta, 7(1), 224 229.Robinson, T. 1995. Kandungan Organik Tumbuhan Tinggi. Bandung: ITB.

[4] Meyer, B.N., Ferrigni N. R., Putnam J. E., Jacobsen L. B., Nichols D. E., dan McLaughlin J. L. 1982. Brine Shrimp: A Covenient General Bioassay for Active Plant Constituents. Journal Planta Medica 45: 3134 